\title{
Effect of changes in postoperative spirometry on survival after lung transplantation
}

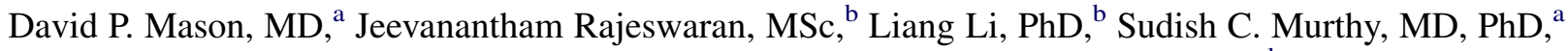 \\ Jang W. Su, MD, ${ }^{a}$ Gösta B. Pettersson, MD, PhD, ${ }^{a}$ and Eugene H. Blackstone, $\mathrm{MD}^{\mathrm{a}, \mathrm{b}}$
}

Objective: The decline in normalized forced 1-second expiratory volume after lung transplantation is inevitable; however, the effect of this change on survival is unknown. Additionally, the benefit of double versus single lung transplant is debated, particularly because pulmonary function is only slightly better after double lung transplant. Our goal was to determine the effect of the temporal pattern of post-transplant forced 1-second expiratory volume (percentage of predicted) on the risk of death after transplant and the differences in the sensitivity of single and double lung transplant to this relationship.

Methods: From February 1990 to January 2008, 622 adults underwent lung transplantation, of whom 315 (51\%) received 2 lungs. Of the 509 patients $(82 \%)$ with available data, 9471 longitudinal evaluations of forced 1 -second expiratory volume (percentage of predicted) were analyzed. The temporal pattern was characterized for each patient, and the resulting curve was evaluated as a time-varying covariable function in the survival analysis. Differences in sensitivity of single and double lung transplant were assessed by interaction.

Results: Forced 1-second expiratory volume (percentage of predicted) increased from 50\% immediately postoperatively to $55 \%$ at 1 year after single lung transplant and then gradually declined to $47 \%$ by 3 years. Although the pattern was similar after double lung transplant, the corresponding forced 1-second expiratory volume (percentage of predicted) at these points was greater-60\%, $75 \%$, and $65 \%$. Lower post-transplant forced 1 -second expiratory volume (percentage of predicted) was associated with a substantially increased risk of death after single lung transplant $(P<.0001)$; however, this increase was far less after double lung transplant $(P<.0001)$.

Conclusions: The results of our study have demonstrated the effect of changing lung function after lung transplantation on survival. Survival after single lung transplant proved more sensitive to declining pulmonary function, demonstrating an advantage of the increased pulmonary reserve provided by double lung transplant. ( $\mathrm{J}$ Thorac Cardiovasc Surg 2012;144:197-203)

Supplemental material is available online.

No study to date has demonstrated the quantitative effect of the temporal pattern of changes in forced 1-second expiratory volume (percentage of predicted [FEV1\%]) on

From the Department of Thoracic and Cardiovascular Surgery, ${ }^{\mathrm{a}}$ Heart and Vascular Institute, and Department of Quantitative Health Sciences, ${ }^{b}$ Research Institute, Cleveland Clinic, Cleveland, Ohio.

This study was supported in part by the Peter and Elizabeth C. Tower and Family Endowed Chair in Cardiothoracic Research, James and Sharon Kennedy, the Slosburg Family Charitable Trust, and Stephen and Saundra Spencer (to G.B. Pettersson), and by the Kenneth Gee and Paula Shaw, PhD, Chair in Heart Research (to E.H. Blackstone). These individuals and funding organizations played no role in the collection of data or analysis and interpretation of the data and had no right to approve or disapprove publication of the finished report.

Disclosures: Authors have nothing to disclose with regard to commercial support.

Received for publication Aug 22, 2011; revisions received Feb 10, 2012; accepted for publication March 14, 2012; available ahead of print May 4, 2012.

Address for reprints: David P. Mason, MD, Department of Thoracic and Cardiovascular Surgery, Heart and Vascular Institute, Cleveland Clinic, 9500 Euclid Avenue,

Desk J4-1, Cleveland, OH 44195 (E-mail: masond2@ccf.org).

$0022-5223 / \$ 36.00$

Copyright (c) 2012 by The American Association for Thoracic Surgery

doi:10.1016/j.jtcvs.2012.03.028 survival after lung transplantation. This is largely because FEV1\% and survival are simultaneously evolving outcomes, and statistical methods to analyze the effect of 1 outcome on another are extremely limited. Although some survival advantage has been demonstrated for double lung transplant over single lung transplant for emphysema and arguably for other transplant indications, post-transplant spirometry is only modestly better. ${ }^{1-4}$ Nonetheless, it has been speculated that the putative survival advantage of double over single lung transplant is secondary to increased post-transplant FEV1\%. Our goal was to determine the effect of the temporal pattern of post-lung transplant FEV1\% on the risk of death after transplant and the differences in the sensitivity of single and double lung transplant to this relationship. For this, we examined spirometry from multiple longitudinal pulmonary function tests to assess temporal trend and developed a novel statistical method to evaluate its effect on survival.

\section{METHODS \\ Patients}

From February 1990 to January 2008, 622 patients older than 18 years underwent primary lung transplantation for end-stage lung disease at 


\section{Abbreviations and Acronyms \\ BOS = bronchiolitis obliterans syndrome \\ FEV1\% = forced 1 -second expiratory volume, percentage of predicted \\ $\mathrm{CL} \quad=$ confidence limit}

Cleveland Clinic, exclusive of heart-lung transplantation. The recipient, donor, and surgical data were extracted from the Unified Transplant Database and Electronic Data Interface for Transplantation. The mean age of the patients at transplantation was $49 \pm 13$ years, and $53 \%$ were men (Table 1).

\section{Spirometry}

The results of spirometry performed in the Cleveland Clinic's certified pulmonary function laboratory, which conforms to the standards of the American Thoracic Society, were retrieved from the Pulmonary Function Test database. These included the National Health and Nutrition Examination Survey-normalized postoperative FEV1\%. ${ }^{5,6}$ A total of 9471 postoperative values were available for 509 patients $(82 \%$ of total population; Figure E1). Patients who died before these tests were performed or whose records could not be located were excluded $(18 \%)$. Nearly one half $(52 / 113)$ of these patients underwent transplantation from 1990 through 1994. During that time, the median interval to the first spirometry assessment was 2.7 years. Of the 52 patients, the median interval to death was 0.94 year, well before lung function would have been assessed. In subsequent years, the median interval to the first spirometry assessment was shortly after transplantation ( 2.5 weeks), and the median interval to death among those not undergoing spirometry was just longer than 1 month. Thus, the predominant reason for not having spirometry data was that the patients were too ill and often died. The Cleveland Clinic protocol for spirometry is now 3 weeks, 3 months, and every 3 months after transplantation and when clinically indicated. All databases used for the present study were approved for use in research by the institutional review board, with patient consent waived.

\section{End Points}

The primary end point in the present study was all-cause mortality. Median follow-up for vital status was 2.7 years from transplant, and 1817 patient-years of data were available for analysis. Twenty-five percent of survivors were followed up for more than 5 years and $10 \%$ for more than 8 years.

\section{Statistical Analysis}

The focus of the present data analysis was twofold: (1) to determine the influence of National Health and Nutrition Examination Surveynormalized postoperative FEV1\% on mortality after lung transplantation, and (2) to test the sensitivity of time-related instantaneous risk of death to FEV $1 \%$ in single versus double lung transplant.

We considered postoperative FEV1\% as a time-varying covariable to assess its influence on survival after transplantation. However, because the postoperative FEV1\% changes over time and is quantified with measurement error, we used the following novel 2-step approach to the analysis: first, to estimate the individual patient trajectory of FEV $1 \%$ over time; and second, to use the collection of these patient-specific trajectories as time-varying covariables in a model of the instantaneous risk of death. Appendix E1 provides a more detailed description of these 2 steps, which are summarized as follows.

Step 1: Patient-specific trajectory. We assumed that each patient's FEV1\% trajectory over time takes the shape of a smooth curve and that the observed zigzag FEV1\% pattern is a result of an underlying "true" FEV1\% trajectory and measurement error. We estimated the patient-specific FEV1\% trajectory by fitting each patient's FEV1\% measurements with a penalized spline if more than 12 measurements were available (324 patients, $64 \%$ ). ${ }^{7}$ If a patient had no more than 2 FEV $1 \%$ measurements, the trajectory was assumed to be a horizontal line over time (21 patients [4\%], 76\% of whom died before the next scheduled spirometry). If a patient had between 3 and 12 FEV1\% measurements, we used a straight-line fit instead of a penalized spline (164 patients [32\%]), because the latter requires a larger sample size.

These patient-specific curves were used as continuous so-called timevarying covariables as described in Step 2. In addition, they were averaged to obtain an overall mean curve for post-transplant FEV1\% and separate mean curves for single and double lung transplant groups.

Step 2: Instantaneous risk of death after transplant. The hazard function for death was estimated by a multiphase hazard model. ${ }^{8}$ Multivariable analysis was performed in the multiphase hazard function domain.

We first identified preoperative and intraoperative risk factors for death as follows: Using the variables listed in Appendix E2, we performed variable selection by bagging (bootstrap aggregation), consisting of automated forward stepwise variable selection, with a $P$ value criterion for retention of variables in the model of .05 , and 500 bootstrap samples. ${ }^{9,10}$ The frequency of occurrence of variables in each of the 500 models was ascertained and indicated their reliability (aggregation step). The variables with bootstrap reliability of $50 \%$ or greater were retained in the analysis.

Once we obtained a multivariable model with preoperative and intraoperative risk factors for death, we forced the patient-specific FEV1\% trajectories into the model as a time-varying covariable function. In addition, a propensity score, using all variables in Appendix E2 except for the maximum ischemic time, was developed using logistic regression analysis and was forced into the survival model. This adjusted for differences in patient characteristics between those receiving single versus double lung transplantation (Figures E2 and E3).

Presentation. Simple descriptive statistics were used to summarize the data. Continuous variables are presented as the mean \pm standard deviation or as 15 th, 50th (median), and 85th percentiles when the data were skewed. Categorical data are described using frequencies and percentages. Comparisons were made using the chi-square test. All analyses were performed using SAS, version 9.1 (SAS Institute, Cary, NC). Uncertainty was expressed by confidence limits (CLs) equivalent to \pm 1 standard error $(68 \%)$.

\section{RESULTS}

FEV1\% and Single Versus Double Lung Transplant

FEV1\% steadily increased after single lung transplant and peaked at $55 \%$ at 1 year and then gradually declined to $47 \%$ by 3 years; although the pattern was similar after double lung transplant, FEV $1 \%$ at these points was greater $-75 \%$ and $65 \%$ at 1 and 3 years, respectively (Figure 1). Survival after single lung transplant was $99 \%$, $88 \%, 68 \%$, and $53 \%$ at 30 days and 1,3 , and 5 years, respectively. The hazard function was constant at $13 \%$ per year $(68 \%$ CL, 12\%-14\%). Survival after double lung transplant was $99 \%, 91 \%, 77 \%$, and $64 \%$ at 30 days and 1,3 , and 5 years, respectively (Figure 2). The hazard function was constant at $8.9 \%$ per year $(68 \%$ CL, $7.9 \%-10 \%)$. Lower post-transplant FEV1\% was associated with a substantially increased risk of death after single lung transplant $(P<.0001$; Figure 3, $A)$, but this increase was far less after double lung transplant $(P<.0001$; Table 2 and Figure $3, B)$. 
TABLE 1. Recipient, donor, and transplant details stratified by single versus double lung transplantation

\begin{tabular}{|c|c|c|c|c|c|}
\hline \multirow[b]{2}{*}{ Variable } & \multicolumn{2}{|c|}{ Single lung transplant } & \multicolumn{2}{|c|}{ Double lung transplant } & \multirow[b]{2}{*}{$P$ value } \\
\hline & Patients (n)* & Value & Patients (n)* & Value & \\
\hline \multicolumn{6}{|l|}{ Recipient } \\
\hline \multicolumn{6}{|l|}{ Preoperative pulmonary function } \\
\hline FEV1 ( $\%$ of predicted $)$ & 211 & $27 \pm 15$ & 238 & $30 \pm 17$ & .04 \\
\hline FVC ( $\%$ of predicted $)$ & 198 & $52 \pm 15$ & 206 & $46 \pm 18$ & $<.0001$ \\
\hline FEV1/FVC & 198 & $0.54 \pm 0.35$ & 206 & $0.69 \pm 0.39$ & $<.0001$ \\
\hline \multicolumn{6}{|l|}{ Demographics } \\
\hline Age (y) & 245 & $57 \pm 7.1$ & 264 & $42 \pm 13$ & $<.0001$ \\
\hline Women & 245 & $110(45)$ & 264 & $132(50)$ & .2 \\
\hline \multicolumn{6}{|l|}{ Race } \\
\hline White & 245 & $236(96)$ & 264 & $236(89)$ & .003 \\
\hline Black & 245 & $9(3.7)$ & 264 & $23(8.7)$ & .02 \\
\hline Body mass index $\left(\mathrm{kg} / \mathrm{m}^{2}\right)$ & 245 & $25 \pm 4.6$ & 264 & $24 \pm 5.7$ & .0009 \\
\hline Body surface area $\left(\mathrm{m}^{2}\right)$ & 245 & $1.8 \pm 0.24$ & 264 & $1.8 \pm 0.29$ & .005 \\
\hline \multicolumn{6}{|l|}{ Indication for surgery } \\
\hline COPD/emphysema & 245 & $148(60)$ & 264 & $54(20)$ & $<.0001$ \\
\hline$\alpha_{1}$-Antitrypsin deficiency & 245 & $23(9.4)$ & 264 & $11(4.2)$ & .02 \\
\hline Cystic fibrosis & 245 & $0(0)$ & 264 & $85(32)$ & $<.0001$ \\
\hline Bronchiectasis & 245 & $0(0)$ & 264 & $11(4.2)$ & .001 \\
\hline Usual interstitial pneumonitis & 245 & $50(20)$ & 264 & $46(17)$ & .4 \\
\hline Pulmonary arterial hypertension & 245 & $2(0.82)$ & 264 & $16(6.1)$ & .001 \\
\hline Sarcoidosis & 245 & $6(2.4)$ & 264 & $13(4.9)$ & .1 \\
\hline Eisenmenger syndrome & 245 & $0(0)$ & 264 & $7(2.7)$ & .01 \\
\hline \multicolumn{6}{|l|}{ Comorbidities } \\
\hline Diabetes & 219 & $22(10)$ & 237 & $56(24)$ & .0001 \\
\hline Serum creatinine $(\mathrm{mg} / \mathrm{dL})$ & 196 & $0.72 \pm 0.22$ & 225 & $0.74 \pm 0.29$ & .8 \\
\hline \multicolumn{6}{|l|}{ Serology/immunology } \\
\hline \multicolumn{6}{|l|}{ Blood type } \\
\hline A & 245 & $103(42)$ & 264 & $107(41)$ & .7 \\
\hline $\mathrm{AB}$ & 245 & $9(3.7)$ & 264 & $9(3.4)$ & .9 \\
\hline B & 245 & $22(9.0)$ & 264 & $39(15)$ & .04 \\
\hline $\mathrm{O}$ & 245 & $111(45)$ & 264 & $109(41)$ & .4 \\
\hline $\mathrm{Rh}+$ & 245 & $204(83)$ & 263 & $212(81)$ & .4 \\
\hline \multicolumn{6}{|l|}{ Donor } \\
\hline \multicolumn{6}{|l|}{ Demographics } \\
\hline Age (y) & 241 & $38 \pm 15$ & 258 & $35 \pm 15$ & .02 \\
\hline Women & 242 & $117(48)$ & 259 & $138(53)$ & .3 \\
\hline Race (white) & 242 & $218(90)$ & 260 & $208(80)$ & .002 \\
\hline Body mass index $\left(\mathrm{kg} / \mathrm{m}^{2}\right)$ & 242 & $25 \pm 5.6$ & 259 & $25 \pm 5.9$ & .9 \\
\hline Body surface area $\left(\mathrm{m}^{2}\right)$ & 242 & $1.9 \pm 0.28$ & 259 & $1.8 \pm 0.27$ & .5 \\
\hline \multicolumn{6}{|l|}{ Comorbidities } \\
\hline Hypertension & 219 & $42(19)$ & 227 & $40(18)$ & .7 \\
\hline Serum creatinine $(\mathrm{mg} / \mathrm{dL})$ & 224 & $1.0 \pm 1.3$ & 236 & $1.2 \pm 1.1$ & .03 \\
\hline \multicolumn{6}{|l|}{ Serology/immunology } \\
\hline \multicolumn{6}{|l|}{ Blood type } \\
\hline A & 242 & $76(31)$ & 259 & $82(32)$ & 1.0 \\
\hline $\mathrm{AB}$ & 242 & $1(0.41)$ & 259 & $3(1.2)$ & .3 \\
\hline $\mathrm{B}$ & 242 & $16(6.6)$ & 259 & $36(14)$ & .008 \\
\hline $\mathrm{O}$ & 242 & $149(62)$ & 259 & $138(53)$ & .06 \\
\hline $\mathrm{Rh}+$ & 238 & $201(84)$ & 254 & $215(85)$ & 1.0 \\
\hline \multicolumn{6}{|l|}{ Cause of death } \\
\hline Anoxia & 245 & $13(5.3)$ & 264 & $19(7.2)$ & .4 \\
\hline Cerebral bleeding & 245 & $78(32)$ & 264 & $42(16)$ & $<.0001$ \\
\hline
\end{tabular}


TABLE 1. Continued

\begin{tabular}{|c|c|c|c|c|c|}
\hline \multirow[b]{2}{*}{ Variable } & \multicolumn{2}{|c|}{ Single lung transplant } & \multicolumn{2}{|c|}{ Double lung transplant } & \multirow[b]{2}{*}{$P$ value } \\
\hline & Patients (n)* & Value & Patients (n)* & Value & \\
\hline Central nervous system tumor & 245 & $3(1.2)$ & 264 & $3(1.1)$ & .9 \\
\hline Stroke & 245 & $54(22)$ & 264 & $67(25)$ & .4 \\
\hline Head trauma & 245 & $87(36)$ & 264 & $115(44)$ & .06 \\
\hline \multicolumn{6}{|l|}{ Recipient-donor mismatch } \\
\hline Donor male, recipient male & 242 & $107(44)$ & 259 & $103(40)$ & .3 \\
\hline Donor female, recipient female & 242 & $90(37)$ & 259 & $111(43)$ & .2 \\
\hline Donor male, recipient female & 242 & $18(7.4)$ & 259 & $18(6.9)$ & .8 \\
\hline Donor female, recipient male & 242 & $27(11)$ & 259 & $27(10)$ & .8 \\
\hline Rh mismatch & 242 & $34(14)$ & 261 & $40(15)$ & .7 \\
\hline \multicolumn{6}{|l|}{ Transplant } \\
\hline Single left-side transplant & 245 & $122(50)$ & & & \\
\hline Single right-side transplant & 245 & $123(50)$ & & & \\
\hline
\end{tabular}

Data presented as mean \pm standard deviation or $\mathrm{n}(\%)$. FEVI, Forced 1-second expiratory volume; $F V C$, forced vital capacity; COPD, chronic obstructive pulmonary disease. *Patients with data available.

More specifically, the risk of death after lung transplant was increasingly elevated at lower pretransplant FEV1\% in single lung transplant, but was independent of pretransplant FEV1\% after double lung transplant (Table 2 and Figure $3, C$ ). In addition, the risk of death was associated only to a small degree with the pattern of FEV $1 \%$ after double lung transplant, but was substantially more sensitive to this pattern after single lung transplant.

When translated from the risk of death into the probability of surviving for 5 years (Figure 4), for the range of FEV1\% observed with single lung transplantation, the probability of survival ranged from $65 \%$ at FEV1 $70 \%$ of predicted to $30 \%$ at FEV1 $20 \%$ of predicted. The probability of surviving 5 years after double lung transplant was nearly constant, ranging from about $65 \%$ to $70 \%$ for the span of observed FEV1. This relationship suggests an

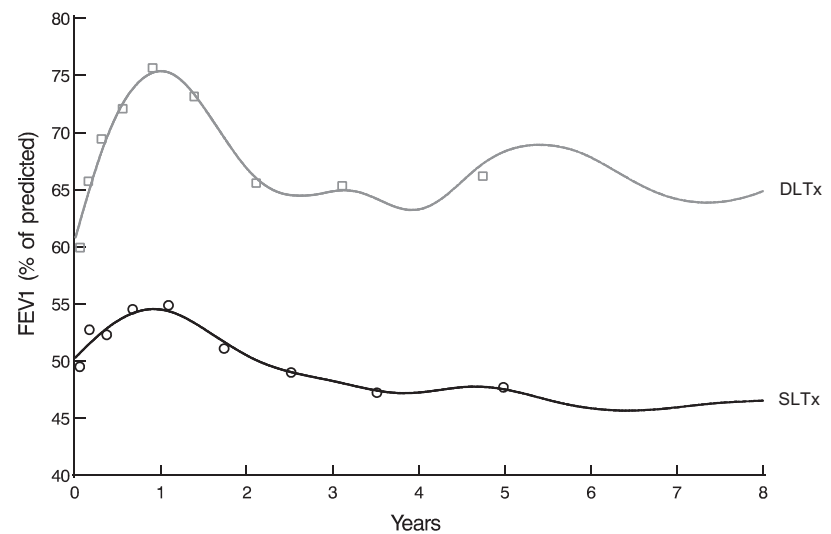

FIGURE 1. Forced 1-second expiratory volume (FEV1\% of predicted) after lung transplantation for single (SLTx) versus double (DLTx) lung transplant. Solid lines represent nonparametric estimates of mean spirometry values across time. Symbols are actual grouped data, without regard to repeated measurements, used as a crude verification of model fit. evident difference in mortality when FEV1 decreases to less than about $50 \%$ to $60 \%$ of predicted.

The predominant modes of death after both single and double lung transplant were respiratory failure, infection, and cardiovascular (Table E1). Respiratory failure was more common after single lung transplant $(P=.009)$.

\section{DISCUSSION}

Survival and postoperative allograft function (spirometry) are considered the 2 most important outcomes after lung transplantation. ${ }^{11}$ FEV1\% is the standard indicator of pulmonary function after transplant because of the simplicity of the test and ease of longitudinal follow-up. ${ }^{12} \mathrm{~A}$ recipient's FEV1\% typically increases to a plateau in the first postoperative year. ${ }^{3}$ A decline from an established baseline is considered the hallmark feature of bronchiolitis

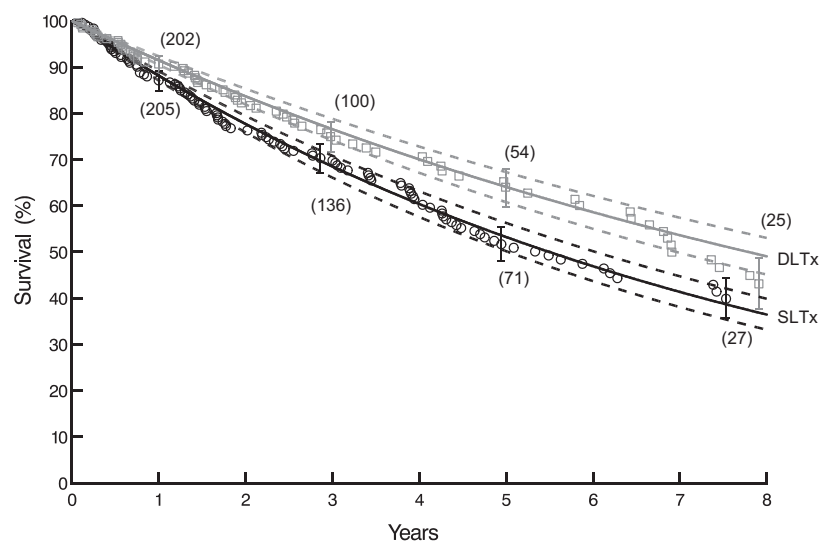

FIGURE 2. Survival after lung transplantation stratified by single (SLTx) and double $(D L T x)$ lung transplant. Solid lines represent parametric estimates of survival enclosed within $68 \%$ confidence bands equivalent to \pm 1 standard error. Symbols represent each death positioned on a vertical axis using the Kaplan-Meier estimator. Vertical bars are $68 \%$ confidence limits equivalent to \pm 1 standard error, and numbers in parentheses represent patients remaining alive and traced. 

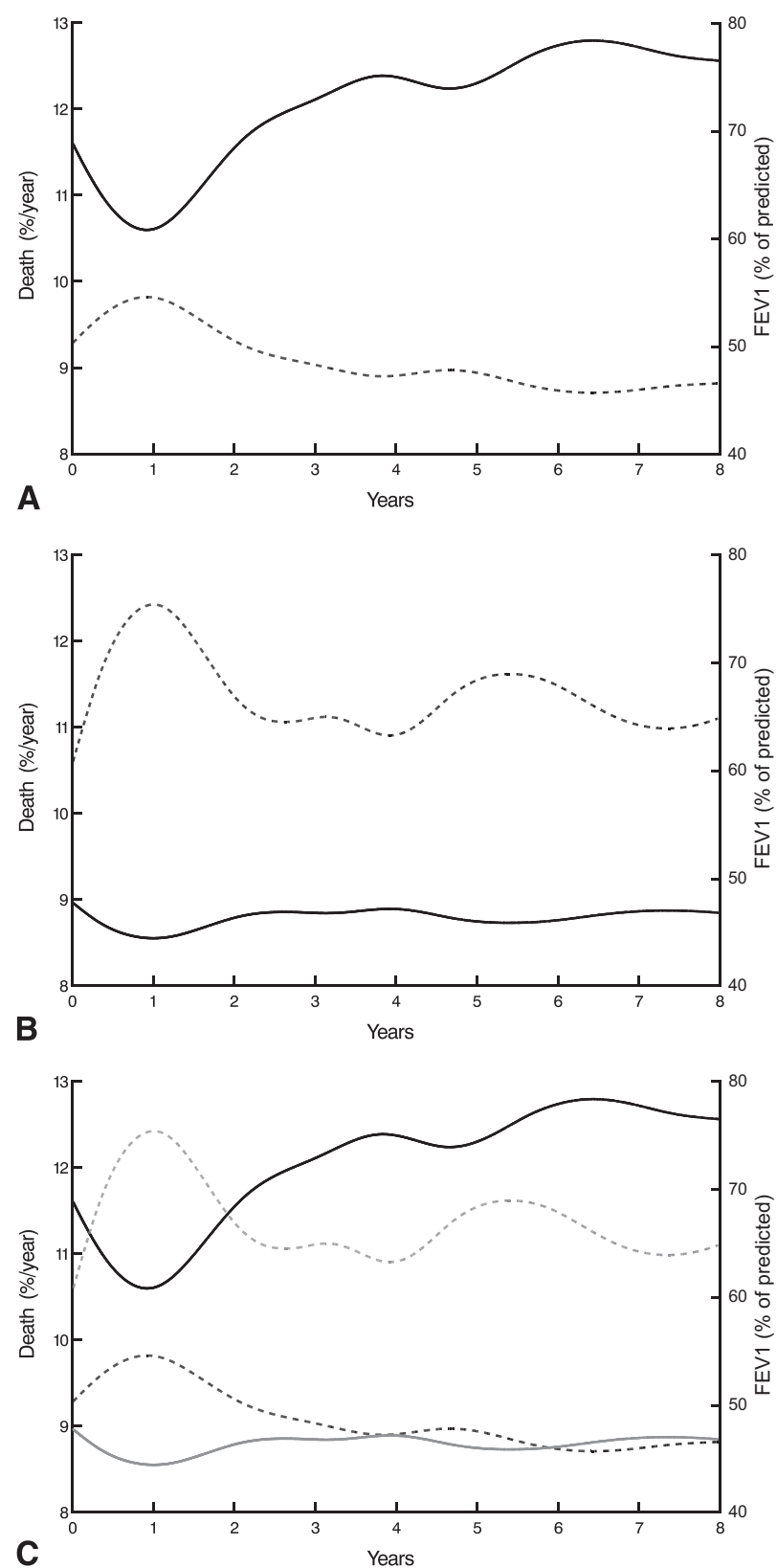

FIGURE 3. Forced 1 -second expiratory volume (FEV1\% of predicted) after lung transplantation (dashed lines) and its influence on hazard of death (solid lines). A, Single lung transplant, (B) double lung transplant, and (C) single lung (black lines) and double lung (gray lines) transplant. Only point estimates depicted.

obliterans syndrome (BOS), the most important cause of mortality after lung transplantation. ${ }^{13}$ BOS reflects small airway obliteration that results from chronic rejection, with the histologic findings described as bronchiolitis obliterans. ${ }^{14}$ Although post-transplant mortality is known to increase after the development of BOS, ${ }^{15}$ the direct effect of declining FEV1\% on survival has not been described, and statistical methods to investigate it have been lacking. Therefore, we evaluated the longitudinal pattern of
TABLE 2. Incremental risk factors for death after lung transplantation

\begin{tabular}{|c|c|c|}
\hline Factor & Coefficient \pm SE & $P$ value \\
\hline Older age* & $0.77 \pm 0.28$ & .006 \\
\hline Bronchiectasis or cystic fibrosis & $0.60 \pm 0.25$ & .02 \\
\hline Lower donor creatinine $\dagger$ & $0.26 \pm 0.12$ & .04 \\
\hline Single lung transplant & $1.8 \pm 0.48$ & $<.0001$ \\
\hline \multicolumn{3}{|l|}{ Preoperative } \\
\hline $\begin{array}{l}\text { Interaction: double lung transplant } \\
\text { and lower pretransplant FEV1\% } \%\end{array}$ & $-0.076 \pm 0.22$ & .7 \\
\hline $\begin{array}{l}\text { Interaction: single lung transplant } \\
\text { and lower pretransplant FEV } 1 \% \S\end{array}$ & $-0.60 \pm 0.19$ & .002 \\
\hline \multicolumn{3}{|l|}{ Postoperative } \\
\hline $\begin{array}{l}\text { Interaction: double lung transplant } \\
\text { and lower post-transplant FEV1\% }\end{array}$ & $-0.38 \pm 0.071$ & $<.0001$ \\
\hline $\begin{array}{l}\text { Interaction: single lung transplant } \\
\text { and lower post-transplant FEV1\% }\end{array}$ & $-2.3 \pm 0.24$ & $<.0001$ \\
\hline Propensity score & $0.12 \pm 0.36$ & .7 \\
\hline
\end{tabular}

FEV1\% on post-transplant survival with a specific focus on single versus double lung transplant.

\section{Effect of FEV1\% on Overall Post-Transplant Mortality}

We have shown that FEV1\% peaks after both single and double lung transplant at approximately 1 year. FEV $1 \%$ after double lung transplant peaks at a higher level than after single lung transplant, and this benefit endures at all measurement points. As the FEV1\% increases after transplantation, the risk of death decreases. Similarly, as FEV1\% declines, the risk of death increases. Although the risk factors for a decline in FEV1\% after the onset of BOS have been described, the relationship to survival has not. ${ }^{16}$ Additionally, the relationship of FEV1\% on survival but independent of BOS has not been demonstrated. The finding that the risk of death varies inversely with FEV1\% supports its validity and highlights an important clinical observation. In our study, the patients whose spirometry increased in the first year after transplant demonstrated a survival advantage during this period. This finding relates improving graft function with better survival, and although intuitive, was previously unproved. Similarly, as graft function declined, survival worsened, even from relatively high FEV1\% levels. This suggests that regardless of the baseline level, a downward trend in FEV1\% is an ominous sign and must be critically interrogated.

\section{FEV1\% and Single Versus Double Lung Transplant}

The incremental improvement in spirometry of double over single lung transplant seems relatively small and therefore calls into question its clinical value. However, we 


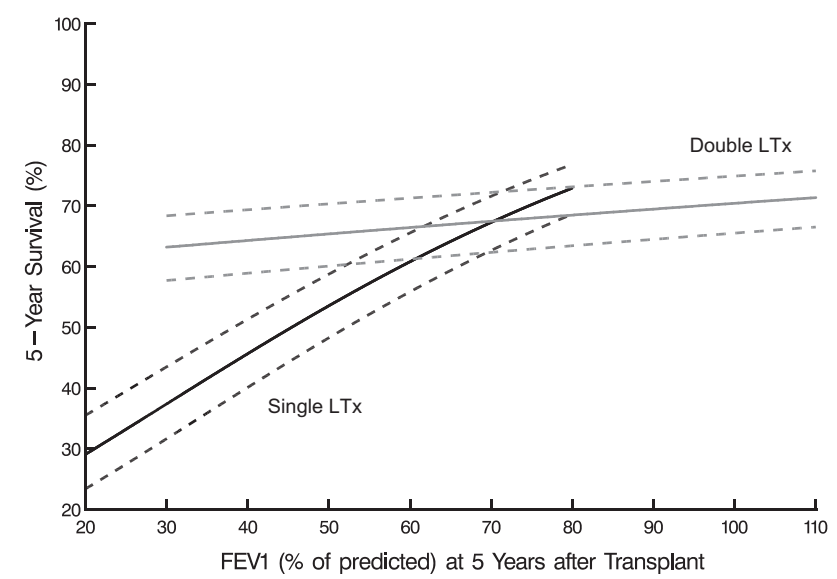

FIGURE 4. Nomogram of multivariable equation presented in Table 2 illustrating the relationship between forced 1-second expiratory volume (FEV $1 \%$ of predicted) at 5 years and survival after single or double lung transplant $(L T x)$. Values for other risk factors were set as follows: age, 49 years; no bronchiectasis or cystic fibrosis; donor creatinine, 0.9 $\mathrm{mg} / \mathrm{dL}$; pretransplant FEV1, 29\% of predicted; propensity score, .5.

found a surprisingly strong benefit of double over single lung transplant when considering the risk of death with FEV1\% decline. Although patients undergoing either single or double lung transplant had substantially increased risk of death when FEV1\% decreased, the effect on double lung transplant recipients was significantly tempered, suggesting a protective effect of larger pulmonary reserve.

Some studies have suggested that double lung transplant offers a protective effect against the development of BOS compared with single lung transplant and a survival benefit once BOS has developed. ${ }^{17}$ However, these findings are subject to potential confounders, including that BOS is defined as a percentage decline against a maximal baseline value, and single lung transplant achieves a lower maximal FEV1\% value than double lung transplant. Thus, patients receiving 2 lungs might be discriminated against and are more likely to be classified as developing BOS than patients receiving 1 lung. ${ }^{18}$ However, the design of our study removes this confounder, evaluates the longitudinal trajectory of FEV1\%, and directly demonstrates the protective effect of double lung transplant when the FEV1\% declines. This finding also highlights the important clinical finding that although a declining FEV1\% after both double and single lung transplant is concerning, it is much more important after single lung transplant.

\section{Study Limitations}

One limitation of the present study is that it represents the clinical experience of a single transplant center. Additionally, the main statistical analysis was conducted on the subset of patients for whom the FEV1\% measurements were available, and the results might not be generalizable to the target population of all lung transplant patients. Although measurements were available for $82 \%$ of patients, those who did not have spirometry data were ill and from the earliest transplant era. However, given the relatively large effect of FEV1\% in predicting death, it is likely that the main conclusion of this analysis still holds qualitatively for the target population.

A limitation of our analysis technique was that a 2-step approach was required to relate patient-specific FEV1\% trajectory with survival. This trajectory was estimated with a semiparametric smoothing method in the first step, and the estimated trajectory was supplied to the multiphase hazard model as a time-dependent covariable function in the second step. This approach might have resulted in bias in the coefficient estimates from the hazard model. However, because many patients have a large number of repeated $\mathrm{FEV} 1 \%$ measurements, and the between-patient variation in FEV1\% is much larger than the withinpatient variation, we expect that the difference between the estimated and true FEV1\% trajectories was small and did not lead to a large bias. A more formal analysis of these types of data that properly adjusts for variation in the first step and eliminates the bias is to jointly model the FEV1\% and survival data. Statistical methodology for such a model is currently under development.

\section{CONCLUSIONS}

The choice of single versus double lung transplant continues to be debated from the perspective of survival, quality of life, and pulmonary function. However, we have shown for the first time that changes in FEV1\% after lung transplantation are related to survival and that double lung transplant appears to provide a survival benefit over single lung transplant when FEV1\% decreases, suggesting a protective effect. This finding should be considered in complex decision making when recommending lung transplantation for a potential recipient as well as in postoperative management.

The authors thank Kevin McCarthy, R-CPT, for providing pulmonary function data, Peter Kisuule, MS, for data management, Lucy Thuita, MS, for statistical programming, and Tess Parry, BS, for editorial assistance and manuscript preparation.

\section{References}

1. Cassivi SD, Meyers BF, Battafarano RJ, Guthrie TJ, Trulock EP, Lynch JP, et al. Thirteen-year experience in lung transplantation for emphysema. Ann Thorac Surg. 2002;74:1663-70.

2. Sundaresan RS, Shiraishi Y, Trulock EP, Manley J, Lynch J, Cooper JD, et al. Single or bilateral lung transplantation for emphysema? J Thorac Cardiovasc Surg. 1996;112:1485-95.

3. Mason DP, Rajeswaran J, Murthy SC, McNeill AM, Budev MM, Mehta AC, et al. Spirometry after transplantation: how much better are two lungs than one? Ann Thorac Surg. 2008;85:1193-201. e1-2.

4. Mason DP, Brizzio ME, Alster JM, McNeill AM, Murthy SC, Budev MM, et al. Lung transplantation for idiopathic pulmonary fibrosis. Ann Thorac Surg. 2007; $84: 1121-8$.

5. American Thoracic Society. Standardization of spirometry, 1994 update. Am J Respir Crit Care Med. 1995;152:1107-36. 
6. Hankinson JL, Odencrantz JR, Fedan KB. Spirometric reference values from a sample of the general U.S. population. Am J Respir Crit Care Med. 1999; 159:179-87.

7. Hastie TJ, Tibshirani RJ. Generalized Additive Models. New York: Chapman and Hall/CRC; 1990.

8. Blackstone EH, Naftel DC, Turner ME Jr. The decomposition of time-varying hazard into phases, each incorporating a separate stream of concomitant information. J Am Stat Assoc. 1986;81:615-24.

9. Breiman L. Bagging predictors. Machine Learning. 1996;24:123-40.

10. Blackstone EH. Breaking down barriers: helpful breakthrough statistical methods you need to understand better. J Thorac Cardiovasc Surg. 2001;122: 430-9.

11. Christie JD, Edwards LB, Kucheryavaya AY, Aurora P, Dobbels F, Kirk R, et al. The Registry of the International Society for Heart and Lung Transplantation: twenty-seventh official adult lung and heart-lung transplant report-2010. $J$ Heart Lung Transplant. 2010;29:1104-18.

12. Martinez JA, Paradis IL, Dauber JH, Grgurich W, Richards T, Yousem SA, et al. Spirometry values in stable lung transplant recipients. Am J Respir Crit Care Med. 1997;155:285-90.
13. Estenne M, Maurer JR, Boehler A, Egan JJ, Frost A, Hertz M, et al. Bronchiolitis obliterans syndrome 2001: an update of the diagnostic criteria. J Heart Lung Transplant. 2002;21:297-310.

14. Estenne M, Hertz MI. Bronchiolitis obliterans after human lung transplantation. Am J Respir Crit Care Med. 2002;166:440-4.

15. Finlen Copeland CA, Snyder LD, Zaas DW, Turbyfill WJ, Davis WA, Palmer SM. Survival after bronchiolitis obliterans syndrome among bilateral lung transplant recipients. Am J Respir Crit Care Med. 2010;182:784-9.

16. Lama VN, Murray S, Lonigro RJ, Toews GB, Chang A, Lau C, et al. Course of FEV(1) after onset of bronchiolitis obliterans syndrome in lung transplant recipients. Am J Respir Crit Care Med. 2007;175:1192-8.

17. Neurohr C, Huppmann P, Thum D, Leuschner W, von Wulffen W, Meis T, et al Potential functional and survival benefit of double over single lung transplantation for selected patients with idiopathic pulmonary fibrosis. Transplant Int 2010;23:887-96.

18. Burton CM, Iversen M, Mortensen J, Carlsen J, Andersen CB, Milman N, et al Post-transplant baseline FEV1 and the development of bronchiolitis obliterans syndrome: an important confounder? J Heart Lung Transplant. 2007;26 1127-34. 


\section{APPENDIX E1. BRIEF DESCRIPTION OF TWO-STEP METHODOLOGY}

The main purpose of our study was to assess and quantify the relationship between postoperative forced 1-second expiratory volume (FEV1\%) and survival after lung transplantation. Time zero is the time of transplantation, and the FEV1\% measurements are measured periodically after transplant. Hence, the natural approach is to treat the postoperative FEV1\% measurements as a time-dependent covariable function in a hazard model to assess the effect of postoperative FEV1\% on survival.

As seen in Figure 2, a parametric hazard model with constant baseline hazard fits our time-to-death data well. Because of only a constant hazard, our multiphase hazard model reduced to a "Cox-type" constant hazard model. Suppose that $Y_{i}(t)$ is the postoperative FEV1 measurement for patient $i$ at time $t$. Then, the "Cox-type" hazard model can be written as

$$
\lambda\left(t, Y_{i}(t)\right)=\lambda_{0} e^{\beta Y_{i}(t)},
$$

where $\lambda_{0}$ is the baseline constant hazard and $Y_{i}(t)$ is the timedependent covariable. However, there is variability in the postoperative longitudinal measurements of FEV1\% owing to measurement error and biologic variation. FEV1\% is a marker for pulmonary function, and there can be variation in this marker over time owing to minor fluctuations in health status and a number of sources of laboratory measurement error, including variation among technicians, changes in equipment, brands of laboratory kits, and repetition error. Therefore, if one does not account for the variability due to measurement error, the regression coefficient $\beta$ in the hazard model will be biased. To address this problem, several authors have proposed different 2-step approaches. ${ }^{\text {E1-E3 }}$ Simply speaking, the 2-step approach is as follows:

STEP 1:

$$
Y_{i}(t)=Y_{i}^{*}(t)+\varepsilon_{i}
$$

where $Y_{i}^{*}(t)$ is the true unobserved covariable value and $\varepsilon_{i}$ is a measurement error. We now estimate the true covariable value at time $t$ based on the observed longitudinal data up to time $t$. We then use this estimated true covariable value in step 2.
STEP 2:

$$
\lambda\left(t, Y_{i}^{*}(t)\right)=\lambda_{0} e^{\beta^{*} Y_{i}^{*}(t)},
$$

where $\beta^{*}$ is the regression coefficient based on the true timedependent covariable $Y_{i}^{*}(t)$.

\section{APPENDIX E2. VARIABLES USED IN THE ANALYSES}

Recipient variables

Demographic: Age (years), gender, race, weight $(\mathrm{kg})$, height $(\mathrm{cm})$, body mass index $\left(\mathrm{kg} / \mathrm{m}^{2}\right)$, body surface area $\left(\mathrm{m}^{2}\right)$

Diagnosis: Usual interstitial pneumonitis, chronic obstructive pulmonary disease, cystic fibrosis, $\alpha_{1}$-antitrypsin deficiency, pulmonary arterial hypertension, sarcoidosis, bronchiectasis, Eisenmenger syndrome, silicosis, other

Spirometry: Preoperative forced 1-second expiratory volume ( $\%$ of predicted) and series of postoperative values

Comorbidities: Diabetes, creatinine (mg/dL)

Serology/immunology: Rh+, blood type A, AB, B, O

Donor variables

Demographic: Age (years), gender, race, weight $(\mathrm{kg})$, height $(\mathrm{cm})$, body mass index $\left(\mathrm{kg} / \mathrm{m}^{2}\right)$, body surface area $\left(\mathrm{m}^{2}\right)$

History: Hypertension, creatinine $(\mathrm{mg} / \mathrm{dL})$

Serology/immunology: Rh+, blood type A, AB, B, O

Cause of death: Anoxia, cerebral bleeding, central nervous system tumor, stroke, head trauma, other

Mismatch variables: Gender, $\mathrm{Rh}+$

Procedure: Maximum ischemic time (min), single or double lung transplant

Experience: Date of operation

\section{E-References}

E1. Raboud J, Reid N, Coates RA, Farewell VT. Estimating risks of progression to AIDS when covariates are measured with error. J R Stat Soc Series A. 1993; 156:393-406.

E2. Tsiatis AA, DeGruttola V, Wulfsohn MS. Applications to survival and CD4 counts in patients with AIDS. J Am Stat Assoc. 1995;429:27-37.

E3. Bycott P, Taylor J. A comparison of smoothing techniques for CD4 data measured with error in a time-dependent Cox-proportional hazards model. Stat Med. 1998;17:2061-77. 


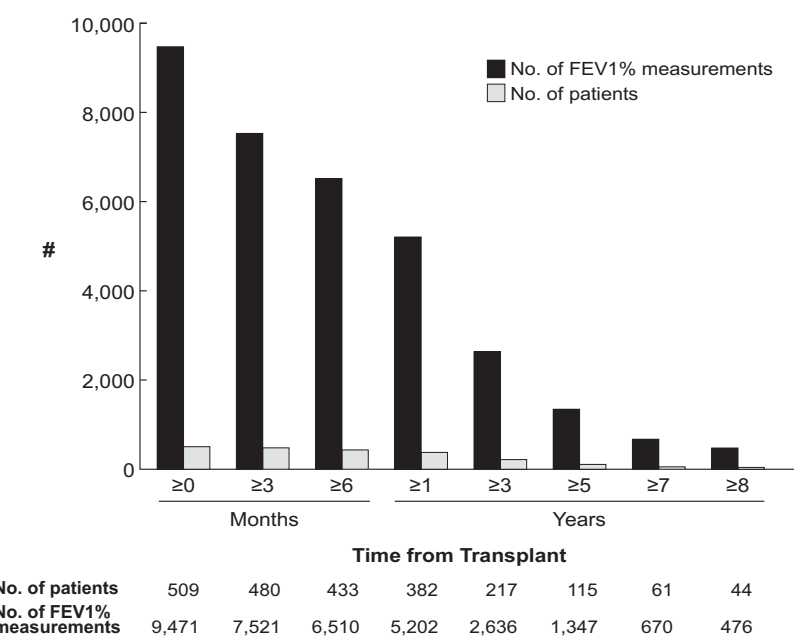

FIGURE E1. Number of patients with spirometry measurements (forced 1-second expiratory volume, percentage of predicted [FEV1\%]) available at and beyond various time points and number of spirometry measurements available for analysis.

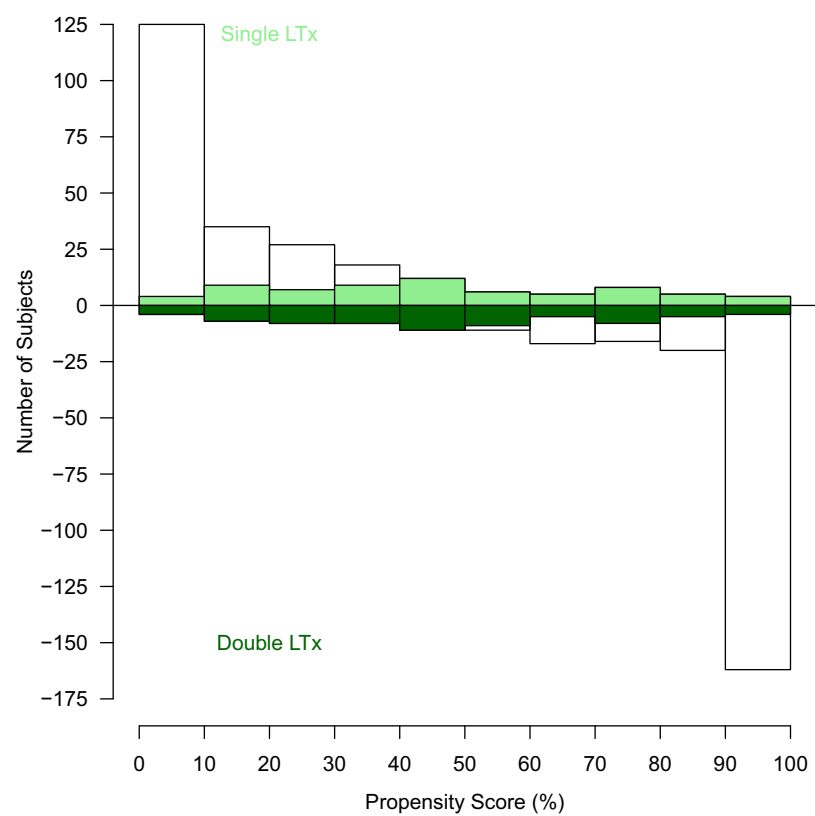

FIGURE E2. Mirrored histogram of distribution of propensity scores for single lung transplant (LTx) (bars above zero line) and double lung transplant (bars below zero line). Darkened area represents matched patient pairs, showing that they cover the complete spectrum of cases.

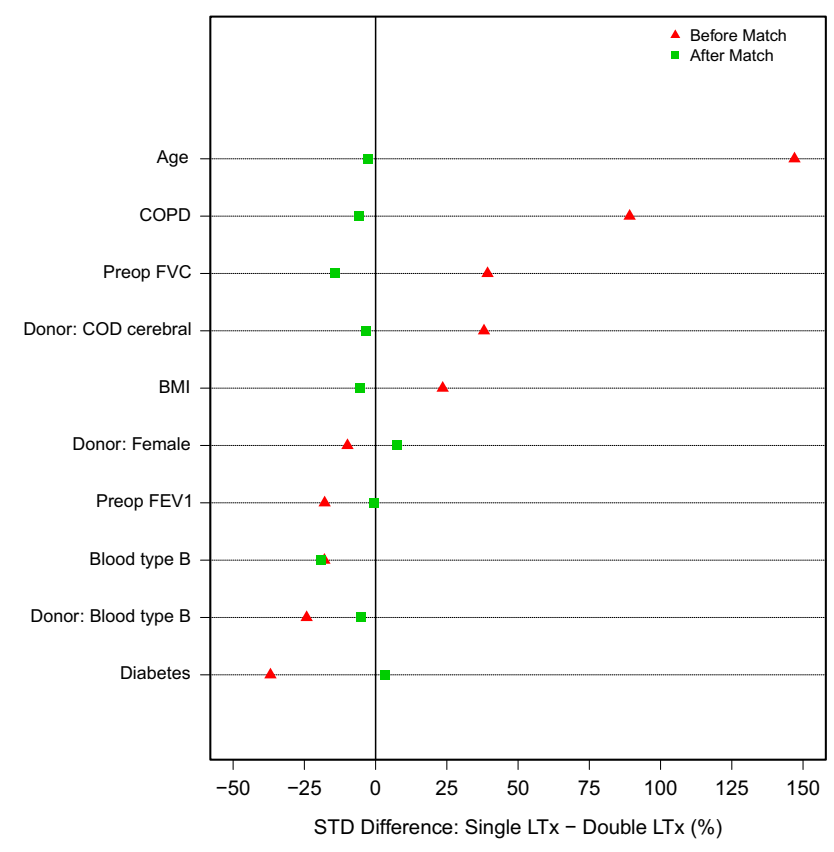

FIGURE E3. Covariable balance for some selected variables before and after matching. Values in $\mathrm{X}$-axis represent percentage of standardized difference* between single lung and double lung transplant groups. BMI, Body mass index; $C O D$, cause of death; $C O P D$, chronic obstructive pulmonary disease; $F E V 1$, forced 1-second expiratory volume; $F V C$, forced vital capacity; LTx, lung transplant; Preop, preoperative. *Austin PC, Mamdani MM. A comparison of propensity score methods: a case-study estimating the effectiveness of post-AMI statin use. Stat Med. 2006;25:2084-106.

TABLE E1. Recipient cause of death

\begin{tabular}{lccc}
\hline \multicolumn{1}{c}{ Variable } & $\begin{array}{c}\text { Single LTx } \\
(\mathbf{n}=\mathbf{2 4 5})\end{array}$ & $\begin{array}{c}\text { Double LTx } \\
(\mathbf{n}=\mathbf{2 6 4})\end{array}$ & $\begin{array}{c}\boldsymbol{P} \\
\text { value }\end{array}$ \\
\hline Respiratory & & & \\
$\quad$ Acute respiratory distress & $3(1.2)$ & $2(0.76)$ & .6 \\
Bronchiolitis & $5(2.0)$ & $7(2.7)$ & .7 \\
Graft failure & $8(3.3)$ & $12(4.5)$ & .5 \\
Respiratory failure & $26(11)$ & $12(4.5)$ & .009 \\
Respiratory hemorrhage & $1(0.41)$ & $2(0.76)$ & .6 \\
Pulmonary embolism & $0(0)$ & $1(0.38)$ & .3 \\
Other pulmonary & $0(0)$ & $1(0.38)$ & .3 \\
Infectious & & & \\
Bacterial infection & $17(6.9)$ & $7(2.7)$ & .02 \\
Viral infection & $3(1.2)$ & $4(1.5)$ & .8 \\
Fungal infection & $6(2.4)$ & $3(1.1)$ & .3 \\
Cardiovascular & & & \\
Cardiac arrest & $5(2.0)$ & $2(0.76)$ & .2 \\
Cardiogenic shock & $1(0.41)$ & $0(0)$ & .3 \\
Anoxia & $1(0.41)$ & $1(0.38)$ & 1.0 \\
Stroke & $1(0.41)$ & $1(0.38)$ & 1.0 \\
Other cerebral & $1(0.41)$ & $0(0)$ & .3 \\
Malignancy & $15(6.1)$ & $6(2.3)$ & .03 \\
Unknown & $11(4.5)$ & $4(1.5)$ & .05 \\
\hline Dan & & &
\end{tabular}

Data presented as $\mathrm{n}(\%) . L T x$, Lung transplant. 